\title{
Biologia reprodutiva e fenologia de Virola sebifera Aubl. (Myristicaceae) em mata mesofítica de Uberlândia, MG, Brasil
}

\author{
EDDIE LENZA ${ }^{1,3}$ e PAULO EUGÊNIO OLIVEIRA ${ }^{2}$
}

(recebido: 3 de novembro de 2005; aceito: 27 de julho de 2006)

\begin{abstract}
Reproductive biology and phenology of Virola sebifera Aubl. (Myristicaceae) in a mesophytic forest of Uberlândia, MG, Brazil). We studied some aspects of the floral and reproductive biology of Virola sebifera Aubl., a dioecious woody species of mesophytic forest in Uberlândia, Minas Gerais. The sex of 54 individuals in the study area was determined in three consecutive reproductive periods. Reproductive phenology of 11 individuals of each sex was followed from October 1998 to April 2000. The sex ratio was always male biased and no sex change was observed, which indicates sexual stability. The flowering was annual, relatively long and massive (cornucopia type) with male individuals blooming earlier and for a longer period than the female ones. Flowers, grouped in paniculate inflorescences, were small ( 3 and $4 \mathrm{~mm}$ long for male and female flowers respectively) and inconspicuous, with an infundibuliforme periant and inserted reproductive whorls. Both male and female flowers have long lifespan (ca. one week). Pollen in male flowers is the sole floral reward. Strong scent and similar flower morphology between sexes may lead to visits to rewardless female flowers (floral self-mimicry). Natural pollination resulted in relatively low number of initiated fruits (5.8\%). Fruit-set from bagged unpollinated flowers (apomixis) were much lower than from natural pollination. These results show that $V$. sebifera depends upon pollination services for seed production although flower visitors were rarely seen during the study and effective pollinators of the species could not be clearly defined.
\end{abstract}

Key words - breeding system, dioecy, floral biology, mimicry, phenology

RESUMO - (Biologia reprodutiva e fenologia de Virola sebifera Aubl. (Myristicaceae) em mata mesofítica Uberlândia, MG, Brasil). Foram estudados aspectos da biologia floral e reprodutiva de Virola sebifera Aubl., uma espécie dióica de mata mesofítica em Uberlândia, Minas Gerais. Foi determinado o sexo de 54 indivíduos presentes na área em três períodos reprodutivos consecutivos. O comportamento fenológico de floração de 11 indivíduos de cada sexo foi acompanhado entre outubro de 1998 e abril de 2000. Houve maior freqüência de indivíduos masculinos na população e nenhum indivíduo mudou de sexo, indicando forte estabilidade sexual na espécie. A floração é anual, massiva e prolongada do tipo cornucópia e os indivíduos masculinos floresceram precocemente e por um período mais longo que os femininos. As flores de $V$. sebifera estão agrupadas em inflorescência do tipo panícula; são pequenas ( 3 e $4 \mathrm{~mm}$ de comprimento para flores masculinas e femininas, respectivamente), inconspícuas, com perianto infundibuliforme e verticilos reprodutivos inclusos. Flores masculinas e femininas apresentaram alta longevidade, superior a uma semana. O único recurso floral é o pólen fornecido pelas flores masculinas. O forte odor e a semelhança morfológica entre flores dos dois sexos (mimetismo floral intra-específico) podem fazer com que flores femininas sejam visitadas pelos agentes polinizadores mesmo sem oferecer recursos florais. O número de frutos iniciados resultantes de polinização natural foi relativamente baixo (5,8\%). A maturação de frutos por apomixia (0,2\%) foi significativamente menor que aquela apresentada por polinização cruzada (1,5\%). Estes resultados demonstram a dependência de $V$. sebifera de agentes polinizadores para a produção de sementes, apesar de que visitantes florais quase não foram observados durante o estudo e os polinizadores efetivos não puderam ser claramente definidos.

Palavras-chave - biologia floral, dioicia, fenologia, mimetismo, sistema reprodutivo

\section{Introdução}

A dioicia em espécies vegetais é caracterizada por populações nas quais os indivíduos produzem exclusivamente flores estaminadas ou pistiladas. Este sistema sexual é apresentado por aproximadamente 6\%

\footnotetext{
1. Universidade de Brasília, Instituto de Biologia, Departamento de Ecologia, Caixa Postal 4631, 70919-970 Brasília, DF, Brasil.

2. Universidade Federal de Uberlândia, Instituto de Biologia, Caixa Postal 593, 38400-902 Uberlândia, MG, Brasil.

3._Autor para correspondência: eddie@unb.br
}

das angiospermas (Renner \& Ricklefs 1995). Em populações de plantas dióicas, algumas diferenças intrasexuais em estratégias reprodutivas, como período de floração e freqüência relativa de indivíduos reprodutivos na população, ou razão sexual, são interpretadas como conseqüência da seleção sexual agindo na separação dos sexos (Bawa 1980a). Segundo a teoria da seleção sexual, estas diferenças ocorrem porque o sexo masculino tem seu sucesso reprodutivo determinado pela quantidade de parceiros potenciais, enquanto que 0 sucesso reprodutivo feminino depende da disponibilidade de recursos para manter a prole (Bateman 1948, Trivers 
1972, Janzen 1977). No caso de plantas dióicas, o sucesso reprodutivo masculino é limitado pelo número de flores femininas polinizadas, enquanto a produção de sementes viáveis e estruturas de dispersão associadas limitam o sucesso reprodutivo feminino (Bawa 1980a, Willson 1994).

A família Myristicaceae tem ampla distribuição nas regiões tropicais e subtropicais do Novo e do Velho Mundo, sendo representada por 59 espécies no território brasileiro (Rodrigues 1982), entre elas Virola sebifera Aubl. (Rodrigues 1980, 1982, Oliveira 1996). No Brasil, a espécie ocorre do Estado do Pará até São Paulo (Lorenzi 2000), sendo comum em cerradões, matas mesofíticas e de galeria do Brasil Central (Rodrigues 1980, Araújo \& Haridasan 1997).

Espécies da família Myristicaceae são predominantemente dióicas (Bawa et al. 1985, Armstrong \& Irvine 1989a, Ackerly et al. 1990, Saraiva et al.1996, Momose et al. 1998), com flores geralmente pequenas e tubulares e polinizadas principalmente por besouros (Armstrong \& Drumnond 1986, Armstrong \& Irvine 1989b, Armstrong 1997, Momose et al. 1998). Os visitantes florais de Myristicaceae utilizam pólen como fonte de recurso floral (Armstrong 1997, Momose et al.1998), fornecido exclusivamente por flores masculinas (Armstrong \& Irvine 1989b, Momose et al. 1998). A ausência de recursos florais em flores femininas poderia constituir um obstáculo à polinização uma vez que os polinizadores poderiam evitar estas flores. Entretanto a polinização é garantida graças à semelhança entre as flores masculinas e femininas, que são visitadas por engano pelos agentes polinizadores, casos típicos de automimetismo floral (Armstrong \& Drummond 1986, Armstrong 1997). Outro mecanismo capaz de aumentar as chances de polinização nestes sistemas miméticos florais intra-específicos é a floração mais precoce de indivíduos masculinos dentro do período reprodutivo (Bawa 1980b, Bullock \& Bawa 1981). Semelhança morfológica e floração precoce de indivíduos masculinos garantem que os agentes polinizadores reconheçam as flores da espécie como potencial fonte de recursos, visitando assim as flores femininas.

No presente estudo, foram analisados aspectos da biologia floral e reprodutiva de Virola sebifera. Aspectos reprodutivos populacionais tais como fenologia, razão sexual e labilidade sexual, foram também analisados. $\mathrm{O}$ objetivo básico do trabalho foi detectar as estratégias ecológicas reprodutivas dos dois sexos e compará-las àquelas observadas em outros representantes da família e também em outras espécies dióicas tropicais.

\section{Material e métodos}

A população de Virola sebifera Aubl. estudada está localizada em mata mesofítica semidecídua, no Parque do


local é cerca de $890 \mathrm{~m}$, a precipitação e temperatura médias anuais são de $1.550 \mathrm{~mm}$ e $22^{\circ} \mathrm{C}$, respectivamente. Na região, predomina o clima tipo Aw, segundo a escala de Köppen (Rosa et al. 1991), caracterizado por duas estações bem marcadas, um verão quente e chuvoso e um inverno frio e seco. Na figura 1 é apresentado um climatograma para o Parque do Sabiá, durante o período de estudo.

Virola sebifera é uma espécie arbórea, atingindo até 30 metros, dióica (Rodrigues 1982), sempre verde, com brotação contínua ao longo do ano e floração durante o período chuvoso (Fernandes-Bulhão 2002).

Em janeiro de 1998 foram marcados, com placas de alumínio, 54 indivíduos reprodutivos da população e medida a circunferência do tronco à altura do peito (CAP). Para os indivíduos que apresentaram ramificações, foram medidos todos os ramos e calculada a circunferência quadrática (Scolforo 1993), através da fórmula:

$$
\mathrm{CAP}=\sqrt{\left.\left(\mathrm{CAP}_{1}\right)^{2}+\left(\mathrm{CAP}_{2}\right)^{2}+\ldots+\mathrm{CAP}_{\mathrm{n}}\right)^{2}}
$$

A circunferência média de indivíduos reprodutivos dos dois sexos foi comparada aplicando-se o teste de MannWhitney. Adicionalmente, as circunferências foram agrupadas em cinco classes: $<20 \mathrm{~cm}$; 20,5 a $40 \mathrm{~cm}$; 40,5 a $60 \mathrm{~cm} ; 60,5$ a $80 \mathrm{~cm}$; > $80 \mathrm{~cm}$. O Teste de Komolgorov-Smirnov foi aplicado para comparação dos dois sexos quanto à distribuição nestas classes.

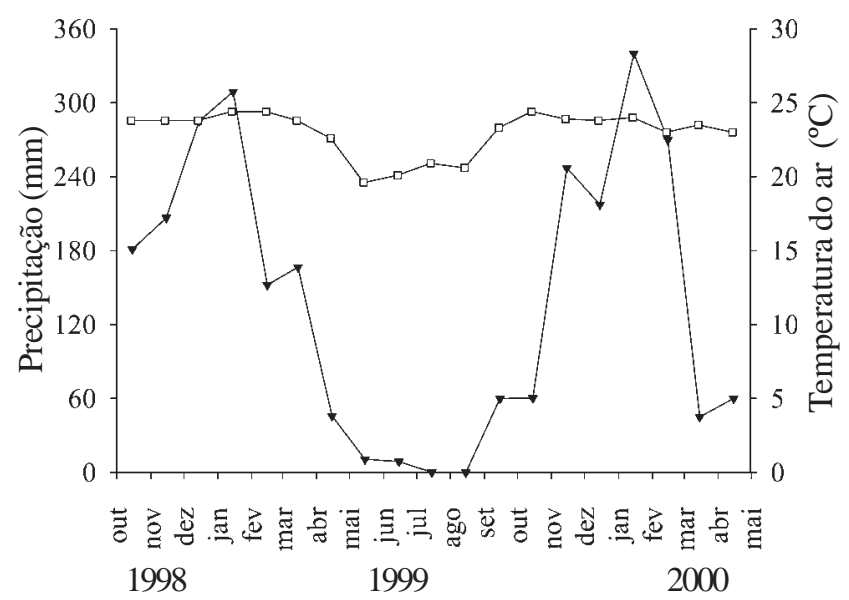

Figura 1. Climatograma do Parque do Sabiá, Uberlândia, MG, durante o período de estudos fenológicos de uma população de Virola sebifera Aubl. (Myristicaceae). ( $\boldsymbol{\nabla}$ = precipitação mensal; $\square=$ temperatura média mensal).

Figure 1. Climate diagram for the Parque do Sabiá, Uberlândia, MG, during the Virola sebifera Aubl. (Myristicaceae) phenology study period. ( $\boldsymbol{\nabla}=$ rainfall; $\square=$ temperature). 
Em janeiro de 1998, 1999 e 2000 foram analisadas 10 flores de cada indivíduo reprodutivo na população para se caracterizar a expressão sexual e detectar possível mudança de sexo entre períodos reprodutivos consecutivos. A razão entre indivíduos masculinos e femininos nos três períodos reprodutivos (razão sexual) foi analisada através do teste de $\chi^{2}$ de aderência, para verificar se havia domínio de um ou de outro sexo na população.

O padrão fenológico de floração da população foi determinado para onze indivíduos de cada sexo. De outubro de 1998 a início de março de 1999 os censos foram realizados em intervalos que variaram entre uma e cinco semanas. Entre a última quinzena de março de 1999 e abril de 2000 os censos foram realizados em intervalos aproximadamente semanais. Dois períodos reprodutivos foram acompanhados durante as observações fenológicas, o primeiro em 1999 e segundo em 2000. O pico de floração da população foi caracterizado quando mais da metade dos indivíduos estavam com flores. O tempo médio de floração individual para o período reprodutivo de 1999 foi comparado entre os dois sexos através do teste de Mann-Whitney.

Foi realizada análise de distribuição circular para determinar o vetor médio ( $r$ ), o ângulo médio $(\bar{a})$ e testar a uniformidade da distribuição (teste $Z$ de Rayleigh) do início da floração ao longo de um ano, entre outubro de 1998 e setembro de 1999. Os ângulos médios para o início da floração dos dois sexos foram comparados por meio do teste $F$ de Watson-Williams para duas amostras para avaliar se os dois sexos diferiram quanto ao início da floração durante o período reprodutivo de 1999 (Zar 1999). Para realização das análises circulares foi usado o programa ORIANA Versão 2.0 (Kovach 2004).

A morfologia floral foi caracterizada analisando 40 flores (dez flores de quatro indivíduos diferentes) de cada sexo com o uso de estereomicroscópio. Foram determinados o número, a disposição e a cor de cada um dos verticilos florais e medido o comprimento das flores.

Para determinação dos recursos florais, foram ensacadas inflorescências de ambos os sexos contendo botões florais, em fevereiro de 1999. Vinte flores (cinco flores de quatro indivíduos diferentes) de cada sexo que abriram durante a noite foram coletadas às $8 \mathrm{~h} 00$, em três manhãs seguintes à sua abertura (um total de 60 flores de cada sexo). As flores foram analisadas quanto à presença de néctar com o uso de estereomicroscópio. A presença e viabilidade dos grãos de pólen nas flores masculinas foram determinadas através de observações de campo e do uso de carmim acético e análise em microscópio (Radford et al. 1974). A receptividade estigmática das flores femininas foi determinada com o uso de $\mathrm{H}_{2} \mathrm{O}_{2}$ a 3\% (Kearns \& Inouye 1993) e análise em estereomicroscópio.

Em fevereiro de 1999, foi determinado o período de abertura das flores em três inflorescências de um indivíduo de cada sexo. As inflorescências foram marcadas quando possuíam apenas botões florais. A contagem das flores abertas foi feita às $8 \mathrm{~h} 00,13 \mathrm{~h} 00$ e 18h00, durante cinco dias para as flores masculinas e de oito dias para as femininas. $\mathrm{O}$ início da antese foi caracterizado quando as flores apresentavam uma pequena abertura em seu ápice. Para verificar se neste estágio de desenvolvimento as flores já estavam funcionais, foram analisadas 20 flores de cada sexo. As flores masculinas foram avaliadas quanto à abertura das anteras, liberação de grãos de pólen e presença de néctar, enquanto nas flores femininas foi observada a receptividade estigmática e presença de néctar. Foi aplicado teste de $\chi^{2}$ de independência para comparar os dois sexos quanto à freqüência de abertura das flores nos três intervalos de tempo analisados. Adicionalmente, foi aplicado o teste de $\chi^{2}$ de aderência para determinar se a abertura das flores em cada sexo foi predominante noturna ou diurna. Nesta análise, os dois períodos diurnos de observação foram agrupados.

Análises de longevidade floral foram conduzidas em fevereiro e março de 1999. Foram marcadas duas inflorescências contendo apenas botões florais, em um indivíduo de cada sexo. Flores abertas durante a noite (entre $18 \mathrm{~h} 00$ e 6h00) foram acompanhadas em intervalos de vinte e quatro horas, sempre às $8 \mathrm{~h} 00$, nas sete manhãs seguintes à antese. As inflorescências femininas foram isoladas com sacos de organza para evitar a polinização. Em cada observação, foi anotado o número de flores abortadas e murchas ou com sinais de murchamento. Oito flores masculinas e 12 femininas foram coletadas ao fim do experimento e analisadas quanto à presença de recursos florais.

Observações não sistemáticas dos visitantes florais, foram realizadas concomitantemente aos demais experimentos de biologia floral, entre $6 \mathrm{~h} 00$ e $18 \mathrm{~h} 00$, durante todo o período de estudo. Observações esporádicas de visitantes florais foram realizadas no período noturno (em pelo menos quatro noites diferentes) e durante o dia em outras áreas do Município de Uberlândia e Araguari, ambos em Minas Gerais. As observações esporádicas envolveram de um a cinco indivíduos sem um tempo determinado, sendo checadas inflorescências acessíveis e observados visitantes na copa. Visitantes foram observados também dentro de flores fixadas.

A produção e maturação de frutos em condições naturais e por apomixia foram comparadas usando-se teste de $\chi^{2}$. Em cada tratamento, foram contados os botões florais de três inflorescências em quatro indivíduos femininos, em janeiro de 1998. Para avaliação da polinização natural foram marcados 3.859 botões e as inflorescências ficaram expostas aos agentes polinizadores. Para análise da apomixia, foram isolados 4.019 botões com sacos de organza para impedir a polinização das flores. Um mês após a abertura das flores foram contados os frutos formados e estes foram acompanhados, em censos quinzenais, até a sua maturação (julho de 1998).

\section{Resultados}

A população de Virola sebifera Aubl. em 1998 foi constituída por 35 indivíduos masculinos (M) e 19 
femininos $(\mathrm{F})\left(\mathrm{M} / \mathrm{F}=1,84, \chi_{0,05,1}^{2}=4,167, P=0,041\right)$. Em 1999, floresceram 30 masculinos e 17 femininos $\left(\mathrm{M} / \mathrm{F}=1,76, \chi_{0,05,1}^{2}=3,064, P=0,080\right)$, sendo que quatro dos indivíduos masculinos originais não floresceram e um indivíduo masculino e dois femininos morreram após o censo anterior. Em 2000 haviam 29 masculinos e 15 femininos $\left(\mathrm{M} / \mathrm{F}=1,93, \chi_{0,05,1}^{2}=3,841, P=0,050\right)$ sendo que morreram dois indivíduos de cada sexo e três indivíduos masculinos não floresceram. Apesar da morte ou não floração de alguns indivíduos na população, a razão sexual (M/F) foi maior que um nos três períodos, embora tenha sido estatisticamente significativa apenas em 1998 e marginalmente não significativa em 2000. Não foi observada mudança de sexo nos indivíduos observados durante os três períodos reprodutivos analisados.

As CAP médias dos indivíduos masculinos (53,6 \pm $16,7 \mathrm{~cm})$ e femininos $(58,3 \pm 17,2 \mathrm{~cm})$ não foram significativamente diferentes $\left(\chi_{0,05,1}^{2}=1,03, P=0,31\right)$. Os dois sexos também não diferiram significativamente quanto à distribuição nas cinco classes de CAP analisadas $\left(\chi_{0,05,2}^{2}=0,2566, P=0,8796\right)$.

A floração ocorreu entre dezembro de 1998 e maio de 1999 no primeiro período reprodutivo e entre dezembro de 1999 e abril de 2000 (fim das observações fenológicas) no segundo período reprodutivo (figura 2). O pico de floração da população durou aproximadamente 13 e 11 semanas para o primeiro e o segundo períodos

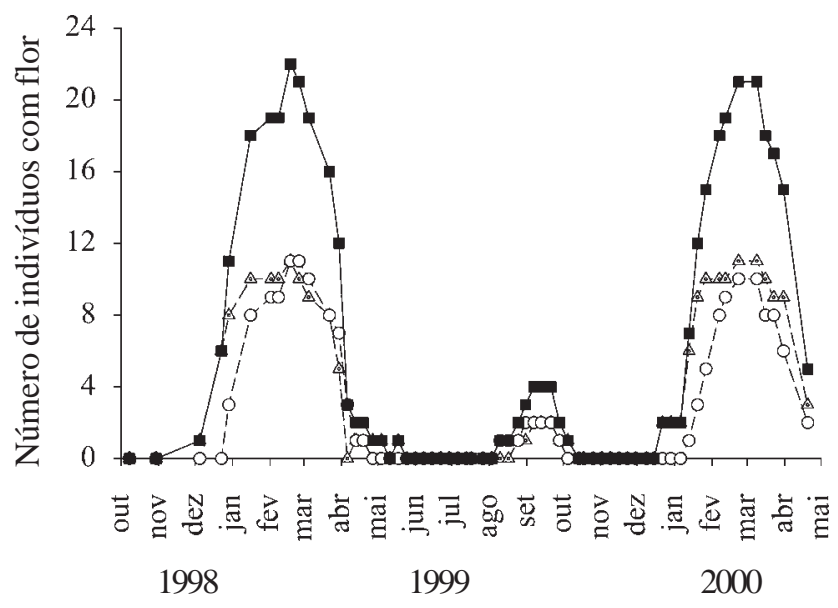

Figura 2. Fenologia de floração de Virola sebifera Aubl. (Myristicaceae) na mata mesofítica semidecídua do Parque do Sabiá, Uberlândia, MG. ( $\triangle$ = indivíduos masculinos; $\mathrm{O}$ = indivíduos femininos; $\mathbf{\square}=$ população).

Figure 2. Flowering phenology of Virola sebifera Aubl. (Myristicaceae) in the mesophytic semideciduous forest of the Parque do Sabiá, Uberlândia, MG. ( $\triangle$ = male individuals; $\mathrm{O}=$ female individuals; $\mathbf{\square}=$ population $)$. reprodutivos, respectivamente (figura 2). Dois indivíduos de cada sexo foram observados em flor em agosto e setembro de 1999 (figura 2), entretanto foram observadas poucas inflorescências isoladas na copa da planta e as inflorescências das duas plantas femininas produziram reduzido número de frutos que não chegaram a maturar.

O vetor médio de concentração $(r)$ do início de floração foi de 0,949 para os 11 indivíduos masculinos e de 0,956 para os 11 indivíduos femininos (valor máximo possível de $r$ é 1). O início da floração para os dois sexos não foi distribuído de maneira uniforme (Teste de Rayleigh, $Z=9,91, P>0,0001$ e $Z=10,05, P<0,0001$ para os indivíduos masculinos e femininos, respectivamente). Estes resultados indicaram que o início da floração dos dois sexos foi sazonal e altamente concentrado. No entanto, os indivíduos masculinos começaram a florescer em média 18 dias mais cedo dentro do período chuvoso, 01 de janeiro de 1999, do que os indivíduos femininos, 19 de janeiro de 1999 (Williams-Watson, $F_{0,05,1,20}=5,009, P=0,037$ ).

O pico de floração foi alcançado aproximadamente três semanas antes para os indivíduos masculinos nos dois períodos reprodutivos analisados, entretanto, o fim do pico de floração para os dois sexos ocorreu simultaneamente (figura 2). O tempo médio de floração dos indivíduos masculinos (96,9 \pm 23,7 dias) foi significativamente mais longo do que aquele dos indivíduos femininos (75,9 $\pm 14,6$ dias $)\left(\chi_{0,05,1}^{2}=6,098\right.$, $P=0,014)$. A maturação dos frutos ocorreu durante a estação seca (entre junho e outubro de 1999).

As flores, dispostas em inflorescências do tipo panícula, são ferrugíneas, levemente zigomorfas, infundibuliformes (com estruturas reprodutivas inclusas), apétalas e possuem três ou quatro sépalas, pilosas e soldadas entre si (figura 3). As flores masculinas possuem aproximadamente $3 \mathrm{~mm}$ de comprimento. Os seis estames, (eventualmente sete ou oito) estão concrescidos em uma coluna central no interior da flor. As anteras são alongadas e possuem deiscência longitudinal (figura 3). As flores femininas medem cerca de $4 \mathrm{~mm}$ de comprimento e possuem um ovário, unilocular, súpero, globoso e piloso (figura 3). O estigma é bilobado (figura 3) e verde quando receptivo. As flores masculinas oferecem pólen como recompensa enquanto as femininas não possuem recurso para os visitantes florais. Néctar ou exudados nunca foram produzidos em quantidades detectáveis nas flores observadas dos dois sexos.

Nos cinco dias de observação das inflorescências masculinas e oito dias para as femininas, foi registrado 

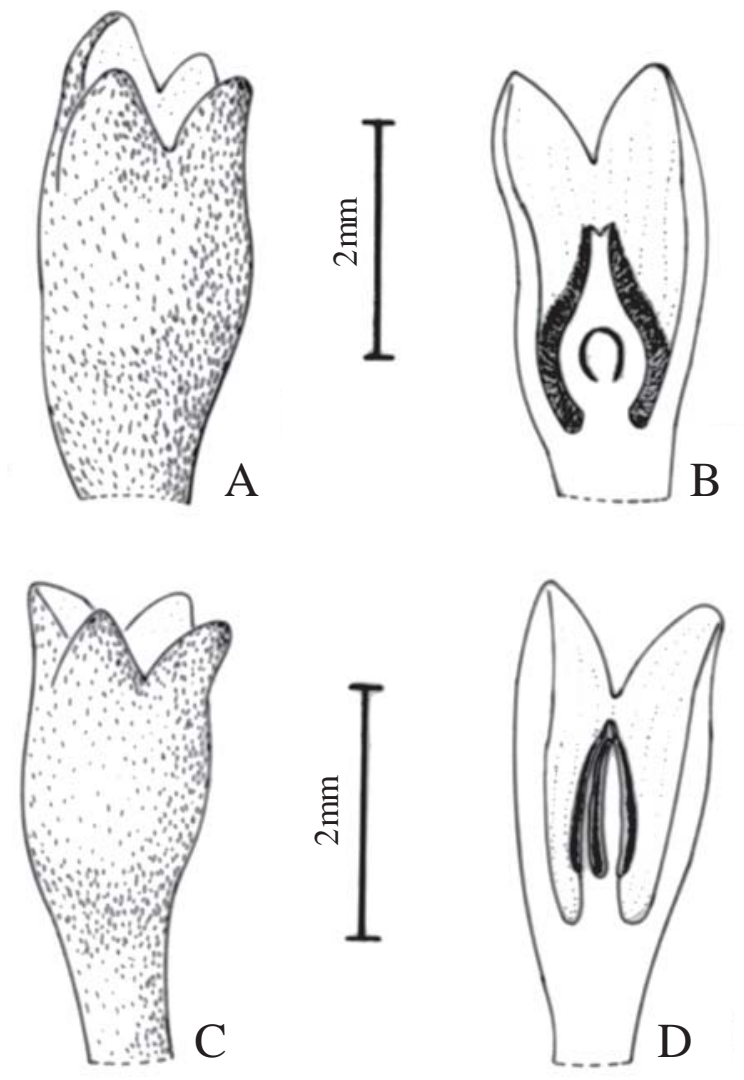

Figura 3. Morfologia floral de Virola sebifera Aubl. (Myristicaceae) na mata mesofítica semidecídua do Parque do Sabiá, Uberlândia, MG. (A e B = flores femininas; C e $\mathrm{D}=$ flores masculinas). $\mathrm{B}$ e $\mathrm{D}$ são cortes longitudinais evidenciando os verticilos reprodutivos.

Figure 3. Flower morphology of Virola sebifera Aubl. (Myristicaceae) in the mesophytic semideciduous forest of the Parque do Sabiá, Uberlândia, MG. (A and B = female flowers; $\mathrm{C}$ and $\mathrm{D}=$ male flowers). $\mathrm{B}$ and $\mathrm{D}$ are longitudinal sections showing reproductive whorls.

um total de 396 flores masculinas e 270 femininas abertas em todos os intervalos de observação (tabela 1). O início da antese foi predominantemente noturno para ambos os sexos $\left(\chi_{0,05,1}^{2}=89,25, P<0,0001\right.$ para flores masculinas e $\chi_{0,05,1}^{2}=21,39, P<0,0001$ para flores femininas). Não houve diferença significativa entre os sexos quanto à freqüência de abertura nos três períodos analisados $\left(\chi_{0,05,2}^{2}=2,41, P=0,2997\right)$.

Em flores parcialmente abertas, o estigma das femininas já estava receptivo e as anteras das masculinas deiscentes e liberando pólen, demonstrando que as flores já eram funcionais neste estágio de desenvolvimento.

As flores dos dois sexos apresentaram alta longevidade. Ao fim do período de observação de
Tabela 1. Período de abertura em flores de Virola sebifera Aubl. (Myristicaceae), em mata mesofítica semidecídua do Parque do Sabiá, Uberlândia, MG.

Table 1. Virola sebifera Aubl. (Myristicaceae) flower opening schedule in the mesophytic semideciduous forest of the Parque do Sabiá, Uberlândia, MG.

\begin{tabular}{lrr}
\hline Período & $\begin{array}{c}\text { Masculina } \\
n(\%)\end{array}$ & $\begin{array}{c}\text { Feminina } \\
n(\%)\end{array}$ \\
\hline 18h00-8h00 & $292(74)$ & $173(64)$ \\
8h00-13h00 & $92(23)$ & $84(31)$ \\
13h00-18h00 & $12(3)$ & $13(5)$ \\
Total & 396 & 270 \\
\hline
\end{tabular}

duração floral, ou seja, na sétima manhã seguinte a antese, foi observada abscisão de apenas sete flores masculinas (6,5\%) e uma flor feminina (3,8\%) (tabela 2). Sinais de murchamento das flores foram observados apenas a partir da quinta manhã para as flores masculinas e da sexta para as femininas (tabela 2). A análise de oito flores masculinas coletadas ao fim do período, mostrou a presença de grãos de pólen ainda viáveis sobre as anteras e na parede interna da flor. Para as 12 flores femininas analisadas ao fim do experimento 11 ainda possuíam estigma verde e receptivo. As observações não puderam ser continuadas após o oitavo dia por questões logísticas e dados os sinais de murchamento observados para ambos os tipos florais, tomados inicialmente como indicativos do final da viabilidade de ambos os morfos florais.

Tabela 2. Longevidade de flores de Virola sebifera Aubl. (Myristicaceae) em mata mesofítica semidecídua no Parque do Sabiá, Uberlândia, MG. (AB = abscisão; $M U$ = flores murchas ou com sinais de murchamento).

Table 2. Flower longevity of Virola sebifera Aubl. (Myristicaceae) in the mesophytic semideciduous forest of the Parque do Sabiá, Uberlândia, MG. (AB = abscission; $\mathrm{MU}=$ wilt flowers or flowers with wilting marks).

\begin{tabular}{|c|c|c|c|c|}
\hline \multirow[t]{2}{*}{ Período } & \multicolumn{2}{|c|}{ Masculina $(n=107)$} & \multicolumn{2}{|c|}{ Feminina $(n=26)$} \\
\hline & $\mathrm{AB}$ & MU & $\mathrm{AB}$ & MU \\
\hline $2^{\mathrm{a}}$ manhã & 0 & 0 & 0 & 0 \\
\hline $3^{a}$ manhã & 2 & 0 & 0 & 0 \\
\hline $4^{\mathrm{a}}$ manhã & 3 & 0 & 0 & 0 \\
\hline $5^{\mathrm{a}}$ manhã & 5 & 5 & 0 & 0 \\
\hline $6^{\mathrm{a}}$ manhã & 7 & 31 & 1 & 2 \\
\hline $7^{\mathrm{a}}$ manhã & 7 & 55 & 1 & 10 \\
\hline
\end{tabular}


Durante as observações diurnas dos visitantes de $V$. sebifera foi coletada apenas uma espécie de Diptera, com quatro indivíduos, todos eles visitando as flores de um único indivíduo do sexo masculino. Foi também observada a visita de um indivíduo de Ornidia obesa (Diptera: Syrphidae) às flores de um indivíduo masculino. Observações noturnas e dissecção de flores fixadas tão pouco permitiram identificar visitantes florais ou polinizadores potenciais. Pequenos Thysanoptera e Homoptera foram observados em flores, mas foi impossível identificar ou avaliar o seu papel no processo de polinização. Dadas às pequenas dimensões florais, apenas insetos muito pequenos como os últimos mencionados são capazes de penetrar na corola das flores masculinas e femininas.

A formação inicial de frutos por apomixia $(n=197$; 4,9\%) não foi significativamente diferente daqueles resultantes de polinização natural $(n=224 ; 5,8 \%)$ $\left(\chi_{0,05,1}^{2}=2,85, P=0,0914\right)$. Entretanto, a maturação de frutos apomíticos $(n=8 ; 0,2 \%)$ foi significativamente mais baixa do que daqueles resultantes de polinização natural $(n=58 ; 1,5 \%)\left(\chi_{0,05,1}^{2}=39613, P<0,0001\right)$.

\section{Discussão}

A ausência de mudança de sexo entre períodos reprodutivos em Virola sebifera Aubl. indica marcante estabilidade na expressão sexual da espécie. Adicionalmente, não foi observada a presença de frutos em indivíduos masculinos durante as análises fenológicas nem foram encontradas plantas produzindo flores do sexo oposto ou mesmo flores apresentando verticilos do sexo oposto, como observado para outras plantas dióicas (Oliveira 1996, Lenza \& Oliveira 2005). Estas características reprodutivas confirmam a idéia do forte controle genético sobre a expressão sexual em plantas dióicas (Bawa 1980a, Rottenberg 1998).

As flores pequenas e inconspícuas de $V$. sebifera são características muito comuns em plantas dióicas tropicais (Bawa 1980a, Sakai et al. 1995, Oliveira 1996) e parecem ser regra em espécies da família Myristicaceae (Rodrigues 1980, Armstrong \& Drummond 1986, Armstrong \& Irvine 1989b, Momose et al. 1998). A morfologia mais especializada das flores de $V$. sebifera, dada pela fusão das sépalas, é uma característica inerente à família (Armstrong \& Drummond 1986; Armstrong \& Irvine 1989b, PiñaRodrigues 1996, Armstrong 1997, Momose et al. 1998), entretanto, também difere da morfologia pouco especializada relatada freqüentemente para espécies unissexuais tropicais, incluindo espécies de cerrado
(Bawa 1980a, Oliveira 1996).

O dimorfismo floral é pouco acentuado entre as flores dos dois sexos, característica morfológica observada em outras espécies da família como Virola surinamensis (Rol) Warb. (Piña-Rodrigues 1996), Myristica insipida R. Br. (Armstrong \& Irvine 1989b, Armstrong 1997) e M. fragrans Houtt. (Armstrong \& Drummond 1986).

A ausência de recursos nas flores femininas de $V$. sebifera, também relatado em outras espécies da família (Armstrong \& Drummond 1986, Armstrong \& Irvine 1989b, Momose et al. 1998), poderia restringir as visitas apenas às plantas masculinas. Entretanto, a semelhança morfológica entre as duas formas florais em espécies dióicas zoófilas tem importante papel para a polinização, pois facilita o reconhecimento das flores e evita a discriminação de flores sem recompensa floral pelos agentes polinizadores (Bawa 1980b, Kay et al. 1984, Freeman et al. 1997). As flores femininas de $V$. sebifera mimetizam as masculinas, sendo possivelmente polinizadas por engano, conforme proposto para outras espécies da família Myristicaceae (Armstrong \& Drummond 1986, Armstrong \& Irvine 1989b, Armstrong 1997) e que está associado à ausência de recompensas em flores femininas (Bawa 1980b, Renner \& Feil 1993).

Tão importante quanto a morfologia floral para a atração de visitantes são as características das inflorescências, que assumem o papel de unidade de atração, e o forte odor exalado pelas flores masculinas e femininas de $V$. sebifera. Esta última característica é muito comum dentro da família Myristicaceae (Armstrong \& Drummond 1986, Armstrong \& Irvine 1989b, Bawa et al. 1990, Momose et al. 1998). Dessa maneira, a atração olfativa comum a ambos os tipos de flores deve ter um papel adicional para o mimetismo floral intra-específico observado em $V$. sebifera, conforme proposto para outras espécies dióicas (Bawa 1980b, Piratelli et al. 1998).

A grande longevidade funcional das duas formas florais de $V$. sebifera deixa as flores expostas aos agentes polinizadores por um tempo longo, elevando as chances de polinização. O horário de abertura teria, dessa forma, um papel secundário para polinização das flores de $V$. sebifera, porque independentemente do período em que as flores abrem, elas podem ficar disponíveis para polinização por até seis noites e seis dias. As duas espécies de Myristica já estudadas tiveram abertura noturna das flores, a despeito de uma ter polinização noturna e a outra diurna (Armstrong \& Drummond 1986, Armstrong \& Irvine 1989b). 
O comportamento de floração da população estudada pode ser caracterizado como cornucópia (Gentry 1974). O longo e ininterrupto período de floração de $V$. sebifera durante o período chuvoso coincide com aquele apresentado por Rodrigues (1980) em estudos de exsicatas de herbário tanto para $V$. sebifera quanto para $V$. oleifera (Schott) AC Smith. A floração por períodos relativamente longos é relatada também para V. surinamensis (Rol.) Warb. (PiñaRodrigues 1996) e parece ser uma característica do gênero (Rodrigues 1980). Fenologia de floração semelhante é também encontrada em Myristica insipida R. Br. na Austrália (Armstrong \& Irvine 1989a).

A floração prolongada observada na população de $V$. sebifera reflete o grande intervalo de tempo que os indivíduos permanecem com flores abertas. Segundo Forfang \& Olesen (1998) as chances de polinização aumentam com a maior duração do tempo de floração individual. Assim, a floração prolongada e a considerável longevidade funcional das flores de $V$. sebifera permitem que os visitantes florais realizem inúmeras visitas em dias distintos elevando níveis de polinização da espécie. Períodos prolongados de floração foram também detectados em 12 espécies brasileiras do gênero (Rodrigues 1980, Piña-Rodrigues 1996).

A floração mais precoce e prolongada para o sexo masculino também foi observada em $V$. sebifera e em duas outras espécies dióicas, Ocotea spixiana (Nees) Mez (Lauraceae) e Diospiros sericea DC. (Ebenaceae), em um cerradão do Distrito Federal (Fernandes-Bulhão 2002). Esse é um fenômeno comum em espécies lenhosas dióicas tropicais (Bawa 1980b, Bullock \& Bawa 1981, Piratelli et al. 1998, Fuzeto et al. 2001). Plantas masculinas florescendo precocemente atraem mais polinizadores (Aronne \& Wilcock 1995), promovendo fluxo direcional de pólen dos indivíduos masculinos para os femininos (Richards 1986) e aumentando o sucesso reprodutivo da população (Piratelli et al. 1998, Armstrong \& Irvine 1989a).

A razão sexual tendendo para o sexo masculino, como observada em $V$. sebifera, é uma característica freqüente em plantas dióicas tropicais (Opler \& Bawa 1978, Thomas \& La Frankie 1993, Oliveira 1996) incluindo espécies de Myristicaceae (Armstrong \& Irvine 1989a, Ackerly et al. 1990). Esses dois últimos autores mostraram que a maior freqüência de indivíduos masculinos florescendo se deve ao alcance precoce do estágio reprodutivo pelo sexo masculino. Esse parece não ser o caso de $V$. sebifera, uma vez que nem a média de CAP dos indivíduos reprodutivos nem a distribuição nas classes de CAP diferiram entre os sexos.
Virola sebifera apresentou baixa formação $(5,8 \%)$ e maturação $(1,5 \%)$ de frutos por polinização natural. Os valores de formação de frutos por polinização natural em $V$. sebifera são comparáveis àqueles encontrados em Myristica insipida (2,3\%; Armstrong \& Irvine 1980a), em seis espécies dióicas de cerrado (entre 0,5 e 9\%; Oliveira 1996) e mesmo em plantas hermafroditas com flores polinizadas por pequenos insetos, como Copaifera langsdorffii Desf. (Leguminosae) (4\%, Freitas \& Oliveira 2002). Entretanto, são inferiores àqueles encontrados para espécies dióicas da região cuja produção de frutos não parece ser limitada por pólen, como Tapirira guianensis Aubl. (Anacardiaceae) (23,5\%) na mesma área de estudo (Lenza \& Oliveira 2005), Cabralea canjerana (Vell.) Mart. (Meliaceae) (32\%) em área de cerrado (Fuzeto et al. 2001) e Jacaratia spinosa (Aubl.) DC. (Caricaceae) (100\%) em floresta semidecídua (Piratelli et al. 1998).

As observações de visitas diurnas às flores de $V$. sebifera foram limitadas. Observações de visitas noturnas ou de flores fixadas tão pouco resultaram na definição dos polinizadores efetivos. Talvez o caráter de fragmento e o grau de perturbação da área de estudo expliquem a raridade de visitantes na área do Parque do Sabiá (F.W. Amorim \& P.E. Oliveira, dados não publicados), mas observações complementares em outras áreas menos antropizadas tão pouco permitiram definir os polinizadores da espécie. As características florais de $V$. sebifera como cor amarela, forte odor, antese diurna e noturna, ausência de néctar e presença de recompensa disponível apenas no interior de uma câmara floral com pequeno poro no seu ápice, correspondem perfeitamente às síndromes florais de espécies polinizadas por besouro pequenos, que parecem ser características da família Myristicaceae (Armstrong \& Drummond 1986, Armstrong \& Irvine 1989b, Armstrong 1997, Momose et al. 1998). Exceção ocorre para as flores $V$. surinamensis (Rol.) Warb., que são visitadas por uma grande variedade de insetos entre eles besouros, formigas, micro-himenópteros, abelhas e vespas (Piña-Rodrigues 1996). Nesta espécie, as flores femininas parecem produzir néctar, possuem órgãos reprodutivos expostos e antese predominantemente diurna (Piña-Rodrigues 1996), características florais que divergem daquelas da síndrome de cantarofilia (Momose et al. 1998).

Com base nas observações do presente estudo, é possível sugerir que os polinizadores de $V$. sebifera sejam insetos muito pequenos, tais como besouros de hábito noturno ou ainda pequenos Thysanoptera e 
Homoptera, capazes de penetrar no tubo da corola em busca de pólen. De qualquer modo, a marcante dificuldade de observação de visitantes florais em plantas abundantemente floridas sugere que a produção de frutos pode ser limitada pelos serviços de polinização na área de estudo. Testes de polinizações manuais poderiam confirmar tais limitações, mas eles foram difíceis de realizar nas diminutas flores de $V$. sebifera.

A maturação dos frutos resultantes dos testes para apomixia em $V$. sebifera foi significantemente mais baixa do que aquela para os frutos resultantes de polinização natural. Mesmo na situação do estudo onde polinizadores potenciais foram raramente observados, a formação de frutos maduros resultantes de polinização natural foi 7,5 vezes maior do que aquela resultante de apomixia. Por outro lado, apesar da pequena proporção de frutos apomíticos, este mecanismo pode ser visto como uma alternativa para produção de frutos em situações onde ocorre deficiência nos serviços de polinização (Richards 1986), como nas áreas de fragmentos florestais resultantes do processo crescente de ocupação e urbanização do Brasil Central (Klink \& Moreira 2002).

Agradecimentos - À Capes e ao CNPq pelo apoio financeiro por meio de bolsa de mestrado para o primeiro autor. Ao Departamento de Ecologia da UnB, ao Instituto de Biologia da UFU e à direção e funcionários do Parque do Sabiá pelo apoio logístico durante a realização do trabalho.

\section{Referências bibliográficas}

ACKERLY, D.D., RANKIN-DE-MERONA, J.M. \& RODRIGUES, W.A. 1990. Tree densities and sex ratios in breeding populations of dioecious Central Amazonian Myristicaceae. Journal of Tropical Ecology 6:239-248.

ARAÚJO, G.M. \& HARIDASAN, M. 1997. Estrutura fitossociológica de duas matas mesófilas semidecíduas, em Uberlândia, Triângulo Mineiro. Naturalia 22:115-129.

ARMSTRONG, J.E. 1997. Pollination by deceit in nutmeg (Myristica insipida, Myristicaeae): Floral displays and the beetle activity at male and female trees. American Journal of Botany 84:1266-1274.

ARMSTRONG J.E. \& DRUMMOND, B.A. 1986. Floral biology of Myristica fragrans Houtt (Myristicaceae), the nutmet of commerce. Biotropica 18:32-38.

ARMSTRONG J.E. \& IRVINE, A.K. 1989a. Flowering, sex ratio, pollen-ovule ratios, fruit set and reproductive effort of a dioecious tree, Myristica insipida (Myristicaceae), in two different rain forest communities. American Journal of Botany 76:74-85.

ARMSTRONG, J.E. \& IRVINE, A.K. 1989b. Floral biology of Myristica insipida (Myristicaceae), a distinctive bettle pollination syndrome. American Journal of Botany 76:86-94.
ARONNE, G. \& WILCOCK, C.C. 1995. Reproductive lability in pre-dispersal biology of Rhamnus alaternus L. (Rhamnaceae). Protoplasma 187:49-59.

BATEMAN, A.K. 1948. Intrasexual selection in Drosophila. Heredity 2:349-369.

BAWA, K.S. 1980a. Evolution of dioecy in flowering plants. Annual Review of Ecology and Systematics11:15-39.

BAWA, K.S. 1980b. Mimicry of male by female flowers and intrasexual competition for pollinators in Jacaratia dolichaula (D. Smith) Woodson (Caricaceae). Evolution 34:467-474.

BAWA, K.S., ASTHON, P.S. \& NOR, S.M. 1990. Reproductive ecology of tropical forest plants: management issues. In: Reproductive ecology of tropical forest plants (K.S Bawa \& M. Hadley, eds.). Unesco, Paris, p.3-12.

BAWA, K.S., PERRY, D.R. \& BEACH, J.H. 1985. Reproductive biology of tropical lowland rain forest trees. I. Sexual systems and incompatibility mechanisms. American Journal of Botany 72:331-345.

BULLOCK, S.H. \& BAWA, K.S. 1981. Sexual dimorphism and the annual flowering pattern in Jacaratia dolichaula (D. Smith) Woodson (Caricaceae) in a Costa Rican rain forest. Ecology 61:1494-1504.

FERNANDES-BULHÃO, C. 2002. Padrões fenológicos de espécies arbóreas do cerradão distrófico na Reserva Ecológica da Embrapa Cerrados, Planaltina - DF. Dissertação de mestrado, Universidade de Brasília, Brasília.

FORFANG, A.S. \& OLESEN, J.M. 1998. Male-biased sex ratio and promiscuous pollination in the dioecious island tree Laurus azorica (Lauraceae). Plant Systematics and Evolution 212:143-157.

FREEMAN, D.C., DOUST, J.L., EL-KEBLAWI, A., MIGLIA, K.J. \& MCARTHUR, E.D. 1997. Sexual specialization and inbreeding avoidance in the evolution of dioecy. Botanical Review 63:65-92.

FREITAS, C.V. \& OLIVEIRA, P.A. 2002. Biologia reprodutiva de Copaifera langsdorffii Desf. (Leguminosae, Caesalpinoideae). Revista Brasileira de Botânica 63:311-321.

FUZETO, A.P., BARBOSA, A.A.A. \& LOMÔNACO, C. 2001. Cabralea canjerana subsp. polytricha (Adri. Juss.) Penn. (Meliaceae), uma espécie dióica. Acta Botanica Brasilica 152:167-175.

GENTRY, A.H. 1974, Flowering phenology and diversity in tropical Bignoniaceae. Biotopica 6:64-68.

JANZEN, D.H. 1977. A note on optimal mate selection by plants. The American Naturalist 111:365-371.

KAY, A.J., BAMBER, F.C. \& DAVIES, C.R. 1984. Differences between sexes in floral morphology, nectar production and insect visits in a dioecious species, Silene dioica. New Phytologist 98:515-529.

KEARNS, C.A. \& INOUYE, D.W. 1993. Techniques for pollination biologists. University Press of Colorado, Niwot. 
KLINK, C.A. \& MOREIRA, A.G. 2002. Past and current human occupation, and land use. In The cerrados of Brazil. (P.S. Oliveira \& R.J. Marquis, eds.). Columbia University Press, New York, p.69-88.

KOVACH, W.L. 2004. Oriana for windows, version 2.0. Kovach Computer Services, Pentraeth.

LENZA, E. \& OLIVEIRA, P.E. 2005. Biologia reprodutiva de Tapirira guianensis Aubl. (Anacardiaceae), uma espécie dióica em mata de galeria do Triângulo Mineiro, Brasil. Revista Brasileira de Botânica 28:179-190.

LORENZI, H. 2000. Árvores brasileiras: manual de identificação e cultivo de plantas arbóreas nativas do Brasil, v.1. $3^{\mathrm{a}}$ ed., Instituto Plantarum, Nova Odessa.

MOMOSE, K., YUMOTO, T., NAGAMITSU, T., KATO, M., NAGAMASU, H., SAKAY, S., HARRISON, R.D., ITIOKA, T., HAMID, A.A. \& INOUE, T. 1998. Pollination biology in a lowland dipterocarp forest in Sarawaka, Malaysia. I. Characteristics of the plant-pollinator community in a lowland dipterocarp forest. American Journal of Botany 85:1477-1501.

OLIVEIRA, P.E. 1996. Dioecy in the cerrado vegetation of Central Brasil. Flora 191:235-243.

OPLER, P.A. \& BAWA, K.S. 1978. Sex ratios in tropical forest trees. Evolution 32:812-821.

PIÑA-RODRIGUES, F.C.M. 1996. Ecologia reprodutiva e conservação de recursos genéticos de Virola surinamensis (Rol.) Warb. na região do estuário Amazônico. Tese de doutorado, Universidade Estadual de Campinas, Campinas.

PIRATELLI, A.J., PIÑA-RODRIGUES, F.C.M., GANDARA, F.B., SANTOS, E.M.G. \& COSTA, L.G.S. 1998. Biologia da polinização de Jacaratia spinosa (Aubl.) ADC. (Caricaceae) em mata residual do Sudeste brasileiro. Revista Brasileira de Biologia 58:671-679.

RADFORD, A.E., DICKSON, W.C., MASSEY, J.R. \& BELL, C.R. 1974. Vascular Plant Systematics. Harper \& Row, New York.
RENNER, S.S. \& FEIL, J.P. 1993. Pollinators of tropical dioecious angiosperms. American Journal of Botany 81:1100-1107.

RENNER, S.S. \& RICKLEFS, R.E. 1995. Dioecy and its correlates in the flowering plants. American Journal of Botany 82:596-606.

RICHARDS, A.J. 1986. Plant breeding systems. George Allen \& Unwin, London.

RODRIGUES, W.A. 1980. Revisão taxonômica das espécies de Virola Aublet (Myristicaceae) do Brasil. Acta Amazônica 10:1-127.

RODRIGUES, W.A. 1982. Flora do Estado de Goiás: Coleção Rizzo (Myristicaceae) (J.A. Rizzo, coord.). Editora da Universidade Federal de Goiás, Goiânia.

ROSA, R., LIMA, S.C. \&ASSUNÇÃO, W.L. 1991. Abordagem preliminar das condições climáticas de Uberlândia. Sociedade \& Natureza 3:91-108.

ROTTENBERG, A. 1998. Sex ratio and gender stability in the dioecious plants of Israel. Botanical Journal oh the Linnean Society 128:137-148.

SAKAI,A.K., WAGNER, W.L., FERGUSON, D.M. \& HERBST, D.R. 1995. Biogeographical and ecological correlates of dioecy in the Hawaiian flora. Ecology 76:2530-2543.

SARAIVA, L.C., CESAR, O. \& MONTEIRO, R. 1996. Breeding systems of shrubs and trees of a Brazilian savanna. Arquivos de Biologia e Tecnologia 39:751-763.

SCOLFORO, J.R. 1993. Mensuração florestal 5: Crescimento florestal $1,1^{\text {a }}$ ed. Esal/Faepe, Lavras.

THOMAS, S.C. \& LA FRANKIE, J.V. 1993. Sex, size, and interyear variation in flowering among dioecious trees of the Malayan rain forest. Ecology 74:1529-1537.

TRIVERS, R.L. 1972. Parental investment and sexual selection. In Sexual selection and the descent of man (B. Campbell, ed.). Aldine, Chicago, p.136-179.

WILLSON, M.F. 1994. Sexual selection in plants: perspectives and overview. The American Naturalist 144:13-39.

ZAR, J.H. 1999. Biostatistical analysis. $4^{\text {th }}$ ed. Prentice Hall, Upper Saddle River. 